Ärztliche Erfahrung beschränkt sich nicht auf medizinisches Fachwissen.

Sie entsteht auch aus den mehr oder minder alltäglichen, heiter, ärgerlich oder nachdenklich stimmenden Erlebnissen mit Patienten, Kollegen und Mitarbeitern. Senden Sie uns Ihre Geschichte an: cornelius.heyer@springer.com.

\title{
Kein Problem für den lebenden Tablettenteiler!
}

_ Neulich kam einer meiner Patienten zu mir in die Praxis. Ich hatte ihn vor ein paar Jahren im Flur der Praxis kennengelernt, weil er sich aufgrund seiner Arztphobie nicht bewegen ließ, sich ins Wartezimmer zu setzen. Damals war er so verängstigt, dass er meinem Angebot, sich ins Sprechzimmer zu setzen, nicht nachkam.

Über die Jahre hat er sich allerdings entspannt. Er hat gemerkt, dass ich ihn zwar immer wieder informiere, wie seine Krankheiten nach den Leitlinien zu behandeln wären, ich aber auch akzeptiere, wenn er nach der ausführlichen Aufklärung seinen eigenen Behandlungsweg einschlägt. Dabei kann ich häufig nur staunen, welche Ansichten und Pläne in seinem Kopf entstehen.
So berichtete er bei seinem letzten Besuch fröhlich, dass er von allen drei Blutdruckmedikamenten jeweils nur noch ein Viertel nähme. Ich schaute in seinen Medikamentenplan und fragte mich, wie er das hinbekommen hatte. Zwei der drei Tabletten hatten noch nicht mal eine Bruchrille, geschweige denn zwei Bruchrillen, um eine Teilung in vier Stücke zu erreichen. Dabei war die Erklärung ganz einfach. „Ich beiße die Tabletten einfach mit den Zähnen ab - wie einen Keks! Die übriggebliebenen Krümel nehme ich dann an den folgenden Tagen", berichtete er stolz. Eine Kontrolle des Therapieerfolgs musste aber wegen seiner Weißkittelhypertonie vorerst ausbleiben.

Dr. Claudia Krite-Anthes, Springe

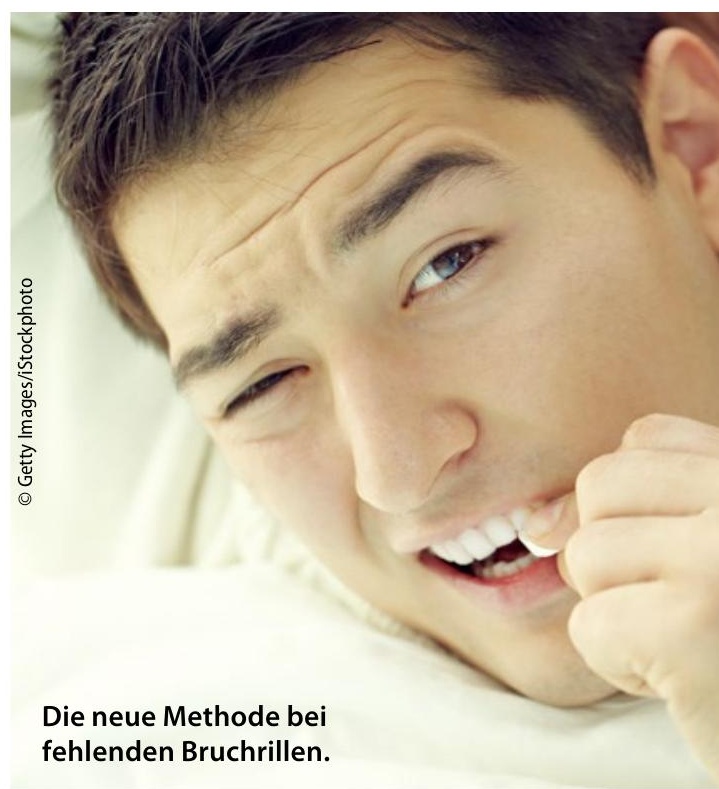

\section{Schmerzen am (deutlich) verlängerten Rücken}

__ Ein Mann mittleren Alters kam etwas steifbeinig, aber nicht humpelnd ins Sprechzimmer und setzte sich sehr vorsichtig hin. Er habe starke Rückenschmerzen, die bis ins Steißbein ausstrahlten, berichtete er. Es sei inzwischen so schlimm, dass er kaum noch sitzen könne. Vor vier Tagen sei er deshalb schon im Krankenhaus gewesen. Dort habe man ihm Tabletten verschrieben, welche die Schmerzen auch zunächst gelindert hätten. Jetzt aber wirkten sie leider kaum noch.
Den Bericht der Kollegen aus der Klinik hatte er vorbildlicherweise mitgebracht. Von Lumbago konnte ich dort lesen, und von einem unauffälligen Routinelabor. Ibuprofen und Pantoprazol wurden rezeptiert.

Ich untersuchte den Patienten selbst. Die Lendenwirbelsäule schien unauffällig, der Druck auf die Iliosakralgelenke provozierte keinen Schmer. „Weiter unten!“, dirigierte der Patient. Skeptisch bat ich ihn nun, sich in Seitenlage hinzulegen - und siehe da, es fand sich ein
Pilonidalabzess an typischer Stelle. Nun ist zwar bekannt, dass die Diskriminationsspanne am Rücken 10 Zentimeter und mehr betragen kann, aber diese Symptombeschreibung war doch deutlich weiter vom Ursprung des Leidens entfernt.

Nur gut, dass ich aus dem Umgang mit Kindern als Patienten gelernt habe, meiner Beobachtung mindestens genauso viel Wert beizumessen wie der Schilderung des Patienten.

Dr. Andrea Linsel, Lüneburg 